\title{
Human extrahepatic biliary atresia: portal connective tissue activation related to ductular proliferation
}

\author{
L. A. R. DE FREITAS ${ }^{12}$, MICHELE CHEVALLIER', DOMINI- \\ QUE LOUIS ${ }^{3}$ AND JEAN-ALEXIS GRIMAUD' \\ 'Laboratoire de Pathologie Cellulaire du Foie, \\ CNRS ERA 819, Institut Pasteur, Lyon, France, ${ }^{2}$ Cen- \\ tro de Pesquisas Gonçalo Moniz, Fundaçao Oswal- \\ do Cruz, UFBA, Salvador, Brazil, and ${ }^{3}$ Centre de \\ Microchirurgie Expérimentale, Institut Pasteur, \\ Lyon, France
}

\begin{abstract}
Surgical bile flow restoration in extrahepatic biliary atresia (EHBA) does not prevent the development of ongoing hepatic fibrosis and cirrhosis. Portal connective matrix was studied on liver biopsies obtained from seven children submitted to portoenterostomy. Electron microscopy and immunohistochemical techniques (using specific antibodies directed against collagen isotypes and associated glycoproteins) were performed. The study of extracellular and cellular components of connective mat ix demonstrated the existence of two distinct areas according to their situation with regard to ductular proliferation: loose connective matrix - mainly composed of fi. . lectin, type III collagen, type IV collagen and laminin - associated with microvessels and myofibroblasts proliferation characterized periportal zones adjacent to bile ductules; in areas distant from ductular proliferation, connective matrix appeared dense, composed of type I and type III collagen associated with fibroblasts. The connective matrix pattern observed in periductular areas can be compared to that described in cicatricial and hypertrophic processes where the myofibroblastic cell population is known to play an important role in fibrosis development. Although the connective matrix activation process remains unclear in EHBA, it may be suggested that activation of a connective tissue cellular clone might be responsible for this portal fibromatosis.
\end{abstract}

Accepted for publication 18 March 1986

Extrahepatic biliary atresia (EHBA) is anatomically defined as obliteration or complete absence of the extrahepatic biliary tree. Consequently, obstruction to bile flow is always observed $(1,2)$. The histopathological findings include cholestasis, ductular proliferation and progressive fibrosis, leading to a pattern of secondary biliary cirrhosis $(3,4)$.

Despite satisfactory porto-enterostomy, functionally checked by re-establishment of bile flow, controlled by normal liver function tests and improvement of jaundice, almost all children present a progressive fibrotic hepatopathy, responsible in the long term for hepatic cirrhosis (5-8). Most of the previous studies on EHBA are related to the diagnosis, prognosis and grading of extrahepatic obstruction for surgical purposes (9-13). Little attention was paid to changes in the portal connective tissue associated with ductular proliferation. However, recent studies on cell-matrix and 
epithelial-mesenchymal interactions $(14,15)$ in $v i$ tro have given new information aiding the understanding of pathogenesis in vivo. Moreover, recent developments in biochemical and immunochemical research on collagens and associated proteins, in normal and pathological conditions, have made relevant precise mapping of connective matrix components in fibrosis (16-18).

In the present study, liver biopsies performed on children with EHBA were submitted to ultrastructural study and immunotyping of collagens and associated proteins in order to characterize this fibrotic process.

\section{Patients and methods}

Liver biopsy specimens were surgically obtained from seven infants during Kasai's porto-enterostomy for complete EHBA. The patients were 1-3 months old and the diagnosis of EHBA was confirmed by cholangiography at the moment of surgery and after histological study of the fibrous tract taken from the site where bile ducts are usually located.

Specimens for histopathological study were fixed in Bouin's solution and were paraffin embedded. Sections of 3-5 $\mu \mathrm{m}$ were cut, transferred to glass slides and submitted to routine staining methods for liver biopsy study (hematoxylin-eosin, Masson's trichrome, orcein, silver stain impregnation and Perl's reaction).

For electron microscopy $1 \% \mathrm{OsO}_{4}$ sodium cacodylate $0.15 \mathrm{M}$ buffered solution was used at $\mathrm{pH} 7.4$. Fixation was carried out at $4^{\circ} \mathrm{C}$ for $60 \mathrm{~min}$. After graded ethanol dehydration, embedding was carried out with Epoxy resin (Epon 812). Sections $1 \mu \mathrm{m}$ thick (made with an LKB or Reichert OMU 2 ultramicrotome) were examined by light microscopy after staining with Richardson's method in order to localize portal and periportal zones. Ultrathin sections were contrasted with uranyl acetate-lead citrate solution and observed on a Philips EM 300 electron microscope.

\section{Collagen immunotyping - preparation of immunologic reagents}

Preparation of antigens. Collagen types I, III and IV were prepared from normal and fibrotic human livers (17). Human fibronectin was isolated from citrate plasma by affinity chromatography using agarose gel. This material was further purified by cellulose-phosphate chromatography in $20 \mathrm{mM}$ potassium phosphate buffer (pH 6.8) containing $1 \mathrm{mM}$ EDTA (19).

Preparation of antibodies. Specific antibodies for collagen isotypes I, pro-III, III and IV were screened for by means of indirect immunofluorescence (17) on human liver and an enzyme-linked immunoadsorbent microassay (ELISA) (20). The peptide $\mathrm{N}$-terminal antigenic determinant on the procollagen type III molecule was recognized by a radioimmunoassay (RIA). For purified anti-basement membrane collagens, no cross-reaction was detectable with laminin using the ELISA microassay.

Anti-laminin antibodies were prepared by injecting rabbits with $0.25 \mathrm{mg}$ of laminin in Freund's complete adjuvant, according to the same procedure as the collagen.

To obtain anti-human fibronectin antibodies, rabbits were inoculated with $500 \mu \mathrm{g}$ of human fibronectin as for

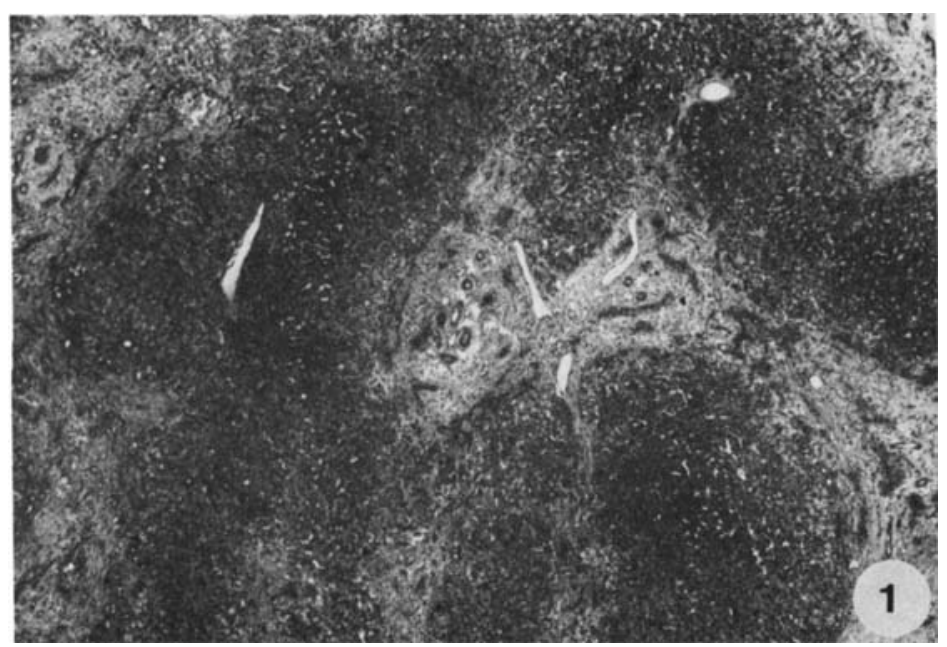

Fig. 1. Cirrhotic stage in a case of EHBA; liver biopsy during Kasai. Hematoxylin-eosin, $\times 150$. 


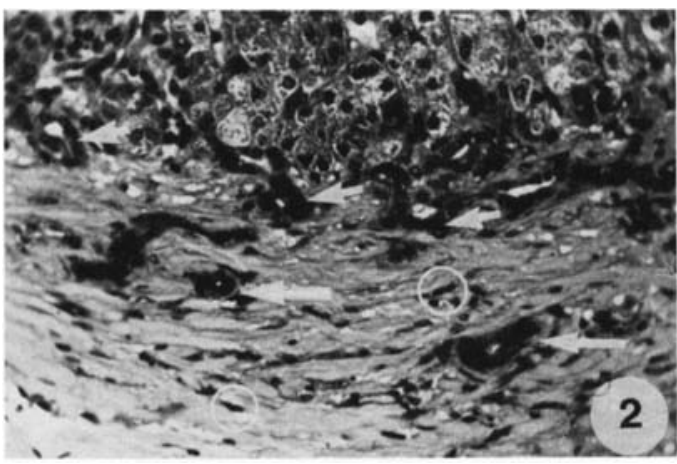

Fig. 2. Ductular proliferation close to the limiting plate of hepatocytes (small arrows); microvessels (large arrows) are seen with numerous elongated mesenchymal cells (O). Hematoxylin-eosin, $\times 300$.

the previous immunization procedure. The presence of anti-human fibronectin antibodies was detected (19). The ELISA and RIA tests were performed before use.

\section{Immunofluorescence staining procedures}

Immunolabelling of collagen types was done by indirect immunofluorescence on $6 \mu \mathrm{m}$ unfixed, frozen sections, using the purified $\operatorname{IgG}$ antibodies $(0.005-0.02 \mathrm{mg} / \mathrm{ml})$ and a fuorescein isothiocyanate (FITC)-labelled sheep antirabbit or rabbit antigoat IgG globulin. All readings

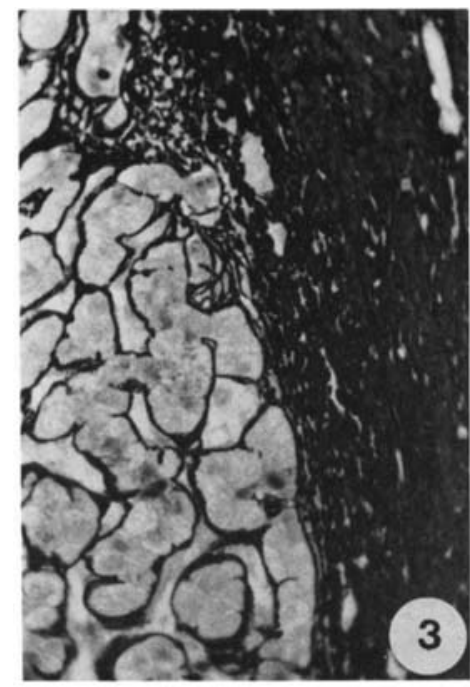

Fig. 3. Periportal zone devoid of ductular proliferation: dense connective matrix organization visualized by reticulin stain. $\times 480$. were performed on a fluorescence microscope fitted with an incident illuminator. Immunofluorescent reactions were controlled by non-immune rabbit serum.

\section{Results}

\section{Light microscopy}

Histopathological study revealed the usual pattern of extrahepatic biliary obstruction (Fig. 1). In all the cases, portal and septal fibrosis, ductular proliferation and cholestasis were the most prominent findings. Giant cell transformation of the hepatocytes was occasionally seen throughout the lobules and hepatocytes, disposed in pseudo-acinar structures, were present around portal zones. In the fibrous tissue adjacent to ductule proliferation, there was proliferation of a spindle-shaped cell, as well as multiplication of small blood vessels (Fig. 2). In these areas ductular proliferation was always associated with a loose pattern of connective matrix organization (Fig. 3), well demonstrated by silver stain. In contrast, areas devoid of ductular biliary proliferation appeared to be composed of dense connective tissue (Fig. 4).

Three specimens showed such extensive fibrosis, with a pattern of micronodular cirrhosis and ductular proliferation, that a diagnosis of secondary biliary cirrhosis was made (Fig. 1).

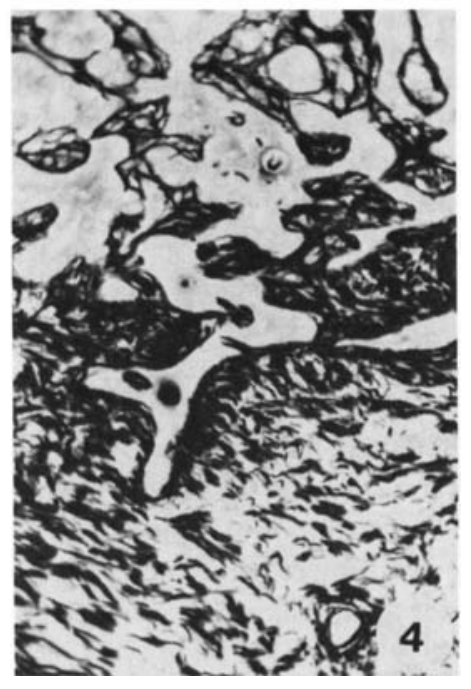

Fig. 4. Loose connective matrix around ductular proliferation. Reticulin stain, $\times 480$. 


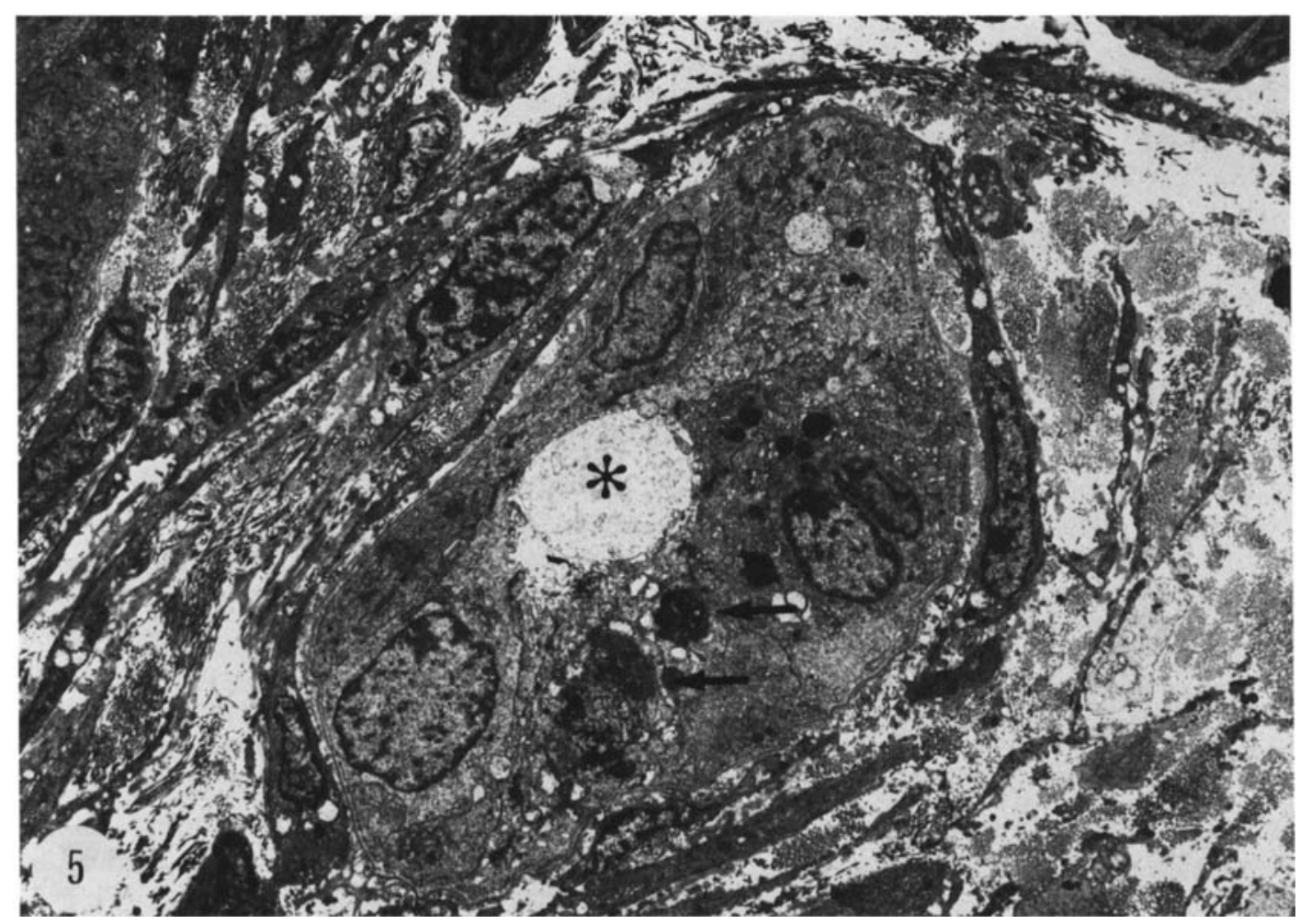

Fig. 5. Bile ductule: numerous cytophagosomes filled with bile pigment (arrows) in ductular cells and protrusion of blebs $\left(^{*}\right)$ in the lumen. $\times 300$.

\section{Electron microscopy}

Hepatic parenchymal cell. Changes in hepatocytes were those related to cholestasis, i.e. bile canalicular dilatation with intraluminal blebs, and intralysosomal biliary pigment storage. A pseudo-acinar arrangement of hepatocytes was frequently observed all over the lobule.

\section{Portal spaces}

\section{Ductular proliferation}

Proliferated bile ductules were mainly located near the lobular limiting plate. They appeared tortuous and irregular, sometimes limited by multilayered basement membranes (Fig. 5 and 6). Ductular cells showed numerous cytophagosomes, mitochondrial swelling and intraluminal blebs (Fig. 5).

Portal connective matrix

As was noted by light microscopic study, two distinct patterns of connective matrix organization were observed:

(1) Areas adjacent to ductular proliferation were characterized by a loose type of organization made of abundant microfibrillar and nonfibrillar components composed of small collagen bundles with poorly oriented fibers. Myofibroblasts were numerous and found around proliferated biliary ductules (fig. 6). These cells were identified as spindle-shaped cells with a central elongated nucleus which was often notched. Like smooth muscle cells, a contractile submembrane apparatus was observed. Parallel to the elongated cell axis, a fibrillar structure showing some areas of increased density appeared characteristic. A fairly well-developed external basement membrane was present. Occasionally, cell junctions were seen between the myofibroblasts (Fig. 7). Frequently cytoplasmic 


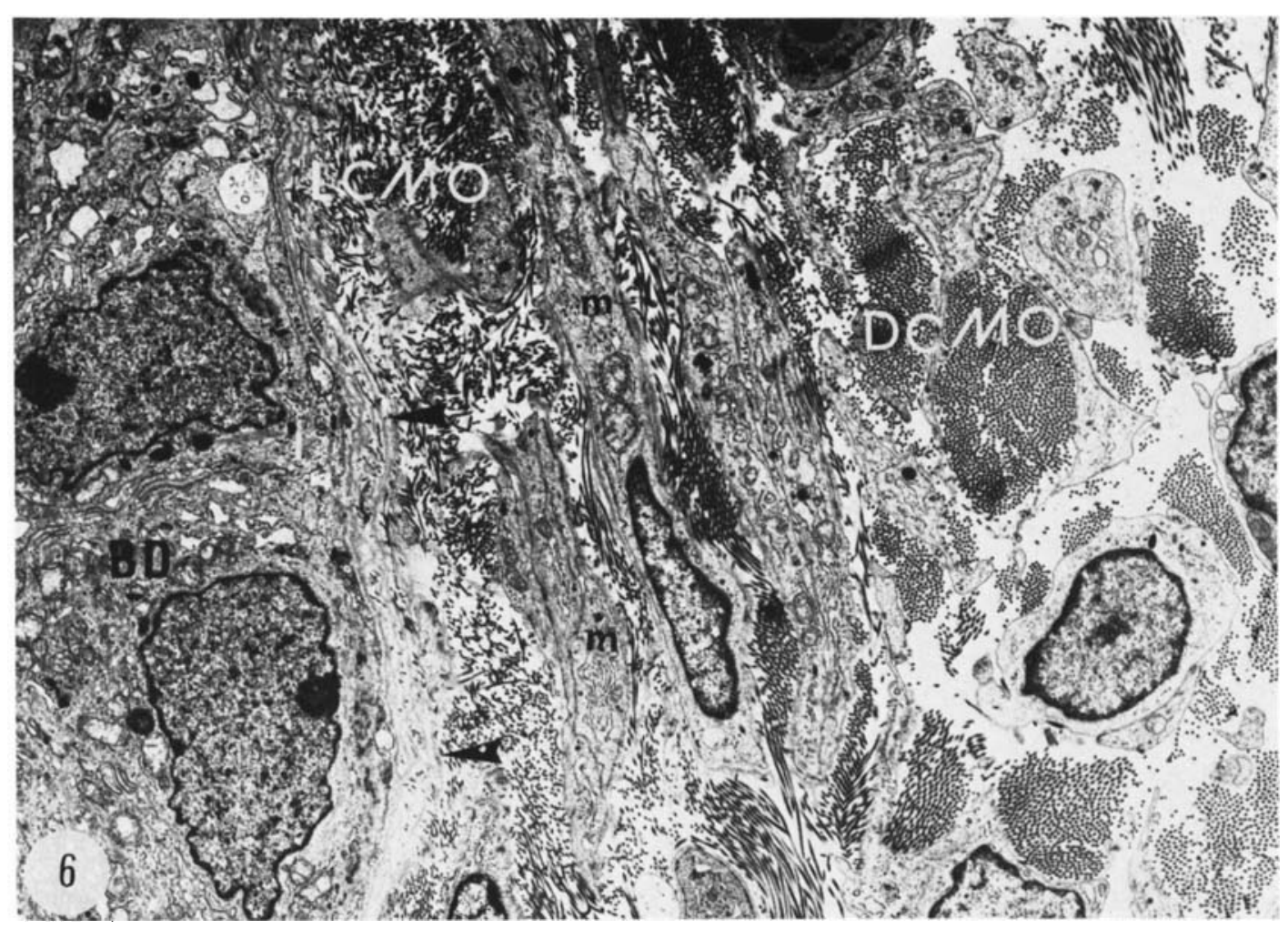

Fig. 6. Myofibroblasts (m) adjacent to a bile ductule (BD): note the multilayered basement membrane of the ductule (arrows) and the connective matrix aspect related to distance from bile ductule; loose connective matrix organization $($ LCMO) near ductular proliferation, dense connective matrix organization $(\mathrm{DCMO})$ in more distant area. $\times 5300$.

vacuoles containing intracytoplasmic fibrillar material identified as collagen fibers were noted in these cells (Fig. 8). In such cases, basement membranes were less clearly seen around the cells (Fig. 8). Proliferated microvessels were represented by capillaries and arterioles. Most of the arterioles had occluded lumina. Their muscular layer was sometimes irregular, hyperplastic and hypertrophic, showing their cells dissociated by edema and the deposition of collagen fibers. Often a file of myofibroblasts disclosed contact with capillary pericytes or with the external muscular layer of the arterioles (Fig. 8).

(2) Areas distant from ductular proliferation were characterized by a dense mode of organization. Large oriented collagen bundles were predominant and associated. Microfibrillar and non-fibrillar components were rarely observed.
Low cell density with predominance of fibroblasts was noted.

A comparative study of the cellular and fibrillar composition of these two portal areas is summarized in Table 1.

Table 1

Electron microscopy of portal connective tissue in EHBA

\begin{tabular}{lcc}
\hline & $\begin{array}{c}\text { Areas adjacent } \\
\text { to ductular } \\
\text { proliferation }\end{array}$ & $\begin{array}{c}\text { Areas distant } \\
\text { from ductular } \\
\text { proliferation }\end{array}$ \\
\hline Bile ductules & $* * *$ & $*$ \\
CM organization & $\begin{array}{c}\text { loose type } \\
\text { Cells MF }\end{array}$ & $\begin{array}{c}\text { dense type } \\
\text { F }\end{array}$ \\
Microvessels & $* * * *$ & $* * *$ \\
\hline
\end{tabular}

***abundant; **moderate number; *rare. CM: Connective matrix; MF: myofibroblasts; F: fibroblasts. 


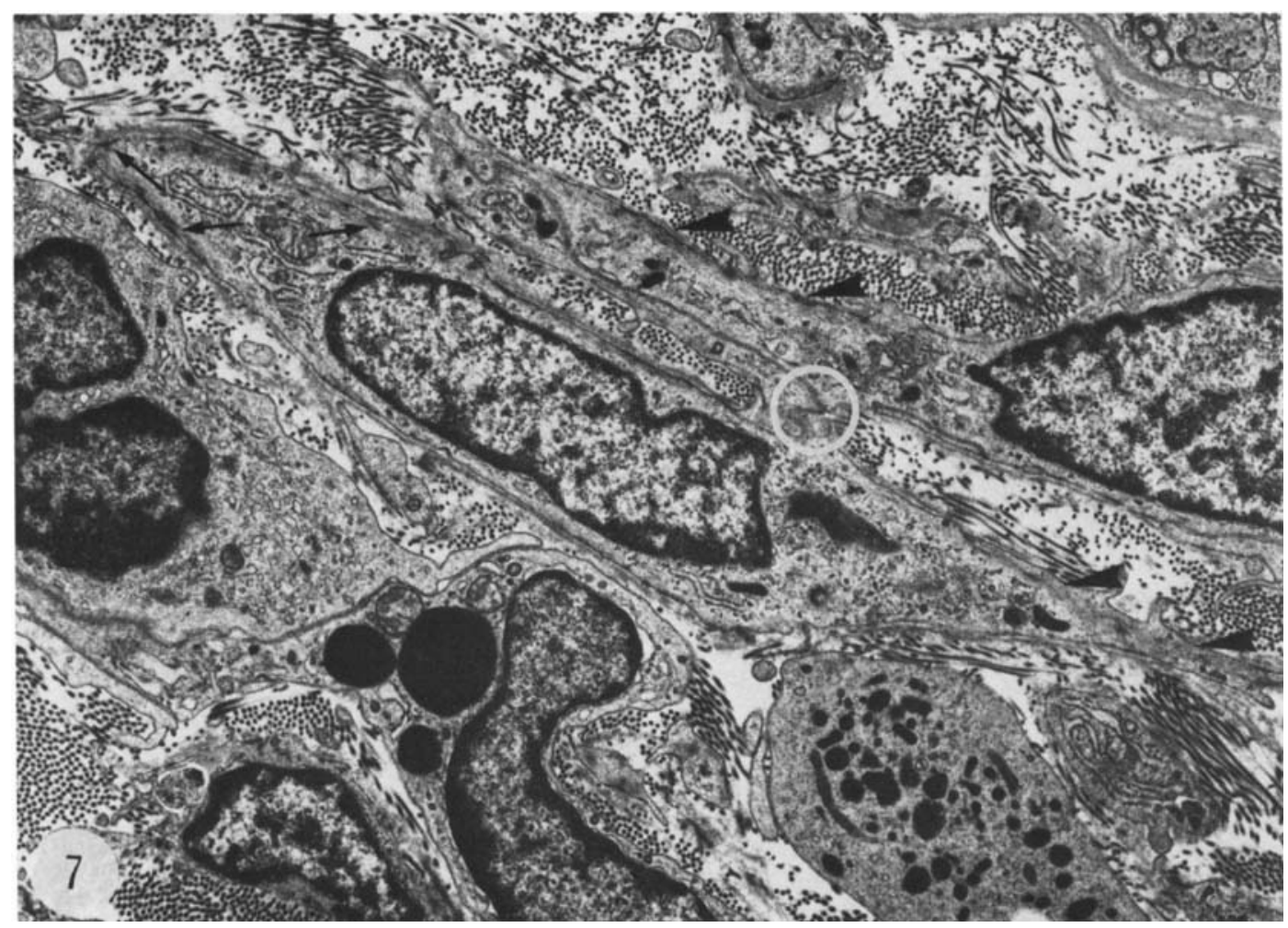

Fig. 7. Ultrastructural criteria for identification of myofibroblasts: spindle-shaped cells lined with basement membrane, submembranous micro-filaments (thick arrows), densifications of membrane (small arrows), and junctions connecting two cells $(0) . \times 800$.

\section{Connective matrix immunolabelling}

Immunofluorescence study using the various antibodies directed against connective matrix demonstrated a diffuse positivity with each isotype antibody against types I, III, IV, pro-III collagen and fibronectin. However, a clear-cut difference existed in the intensity of the reaction, which varied from the marginal to the central part of portal tracts. Thus, type III collagen, pro-III collagen and fibronectin predominated in periductular areas (Fig. 9, 10,11) and decreased towards central zones. In this same region, type IV and laminin labelled the numerous vessels and ductular channels. By comparison, type I and type III collagen formed the main components in the central region of portal tracts. These results are summarized in Table 2.

\section{Discussion}

Our results indicate that in EHBA, ductular proliferation is always associated with significant changes of adjacent connective matrix. This fact has already been described in other diseases of the biliary tract (21). In these cases, the fibrotic reaction is generally associated with and/or follows an inflammatory or a neoplastic process. For example, in cholangitis disappearance of the inflammatory reaction after treatment is followed by stabilization, or even reversal of the fibrotic process.

However in EHBA, inflammation is not generally considered to play the major role in the course of tissue lesions; few inflammatory cells are found in situ and ductular proliferation is often the only change associated with fibrosis. Since the influence of cholestasis cannot be incriminated in the 


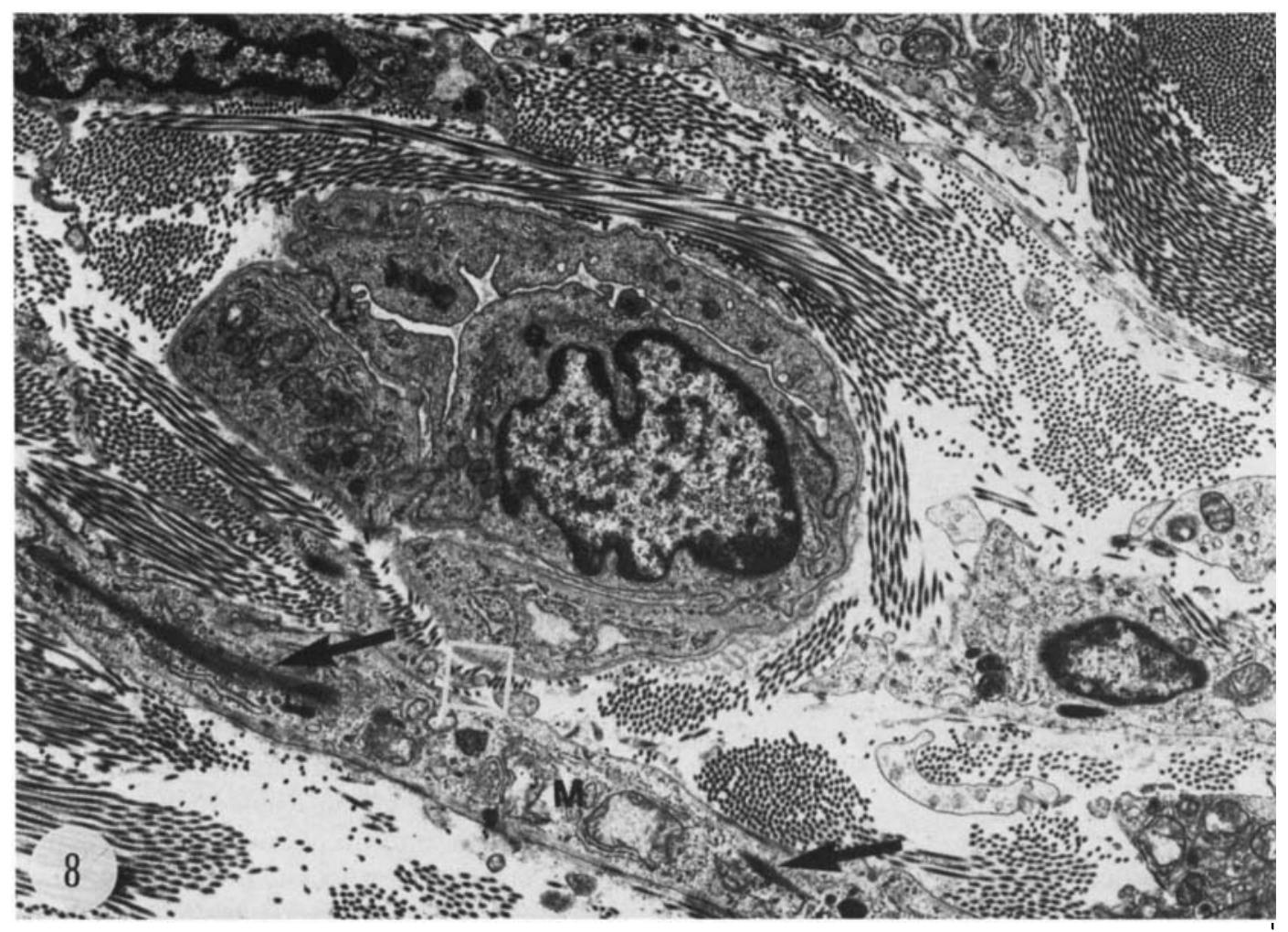

Fig. 8. Cross-section of a microvessel with occluded lumen - note the close contact (square) between pericyte and myofibroblast $(\mathrm{M})$, and collagen fiber-containing vacuoles (arrows) in the myofibroblastic cell. $\times 8000$.

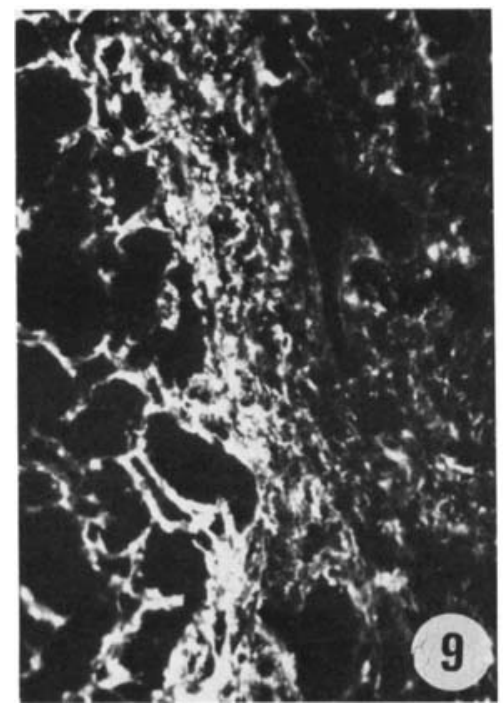

Fig. 9. Portal tract: immunofluorescence of fibronectin. Note the strong positivity near the parenchymal limiting plate, around ductular proliferation. $\times 500$.

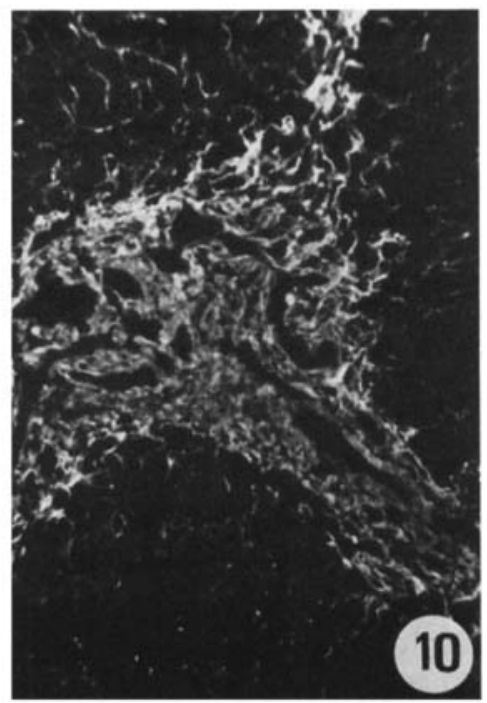

Fig. 10. Portal tract: immunofluorescence of type III procollagen; diffuse and marked positivity of the connective matrix. $\times 300$. 


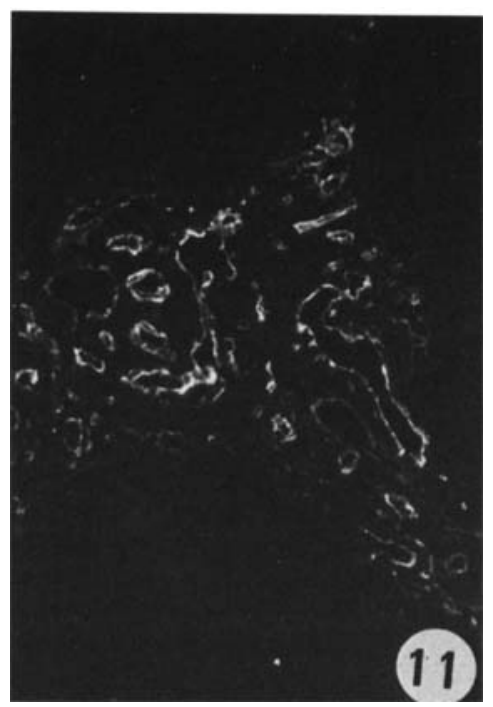

Fig. 11. Same portal tract: immunofluorescence of collagen type IV; abundance of vessels and ducts channels demonstrated by basement membrane staining. $\times 300$.

present disease, evolutive fibrosis seems to be more related to a stroma reaction concomitant with ductular proliferation than a post-necrotic or chronic inflammatory process.

The precise analysis of cellular and matricial elements which participate in the fibrotic reaction in EHBA is of interest for general pathological interpretation. In areas adjacent to ductular proliferation, numerous and active myofibroblasts associated with proliferation of microvessels and loose connective matrix organization, represent a connective tissue pattern very similar to a hypertrophic and cicatricial process which leads to a self-perpetuating mode of evolution, as described in other tissues (22-25). In skin hypertrophic scars and keloids, myofibroblasts are claimed to play a fundamental role in the remodelling process of the granulation tissue $(22,26)$. It can be assumed that the presence of myofibroblasts, whatever may be their origin in EHBA, would have a similar function in portal fibrosis.

Among the myofibroblasts observed in the present study, several appeared to be acting as phagocytes. This fact was demonstrated by the presence of numerous collagen-containing vesicles in the cytoplasm. The relative irregularity of the pericel-
Table 2

Immunolabelling of portal connective matrix proteins in EHBA

\begin{tabular}{lcc}
\hline Matrix protein & $\begin{array}{c}\text { Areas adjacent } \\
\text { to ductular } \\
\text { proliferation }\end{array}$ & $\begin{array}{c}\text { Areas distant } \\
\text { from ductular } \\
\text { proliferation }\end{array}$ \\
\hline Collagen isotype & $*$ & $* *$ \\
I & $* *$ & $* *$ \\
III & $* *$ & $*$ \\
IV & $* * *$ & $*$ \\
Procollagen III & $* * *$ & $*$ \\
Fibronectin & $* *$ & $*$ \\
Laminin & &
\end{tabular}

Degree of fluorescence intensity: ${ }^{* * *}$ marked; ${ }^{* *} \bmod$ erate; *slight.

lular basement membrane of phagocyting myofibroblasts appears to be the only difference between them and the non-phagocytic cells. In skin, these cells have been named myofibroclasts (27). In EHBA it can be assumed that myofibroblasts are directly involved in the remodelling process of portal fibrosis. It seems of interest to note that in EHBA myofibroblast activity is clearly associated with microvessel proliferation. In our study, some pericapillary pericytes were in close contact with the myofibroblast population. It can be speculated that through the pericapillary pericyte, the myofibroblasts are building a diffuse network throughout the connective matrix ready for contraction during the different stages of the fibrotic process.

In EHBA, the precise origin and the exact significance of the connective tissue activation, represented by microvessel and myofibroblast proliferation, remains obscure. As a strong stroma reaction $(23,28,29)$ associated to ductular proliferation, the connective tissue reaction in EHBA appears to be a proliferative fibrosis with self-perpetuating capacities. This characteristic could be related to the great plasticity and proliferative capacities of the connective tissue of children.

It is of interest to note that, after surgical treatment, ductular proliferation disappears but portal fibrosis continues to evolve.

Connective tissue activation could be the result of a clonal activation of connective tissue cells. Consequently, a kind of portal fibromatosis, leading to cirrhosis, might be initiated in situ. 


\section{References}

1. Bill a H, haAs J E, Foster G L. Biliary atresia: histopathologic observations and reflections upon its natural history. J Pediatr Surg 1977: 12: 977-982.

2. Alagille D. Extrahepatic biliary atresia. Hepatology 1984: 4: 75-105.

3. Hollander M, Schaffner F. Electron microscopic studies in biliary atresia. I. Bile ductular proliferation. Am J Dis Child 1968: 116: 49-56.

4. Scotto J M, Stralin H G. Congenital extrahepatic biliary atresia. Arch Pathol Lab Med 1977: 101: 416-419.

5. Gautier M, Valayer J, Odievre M, Alagille D. Histological liver evaluation 5 years after surgery for extrahepatic biliary atresia: a study of 20 cases. $J$ Pediatr Surg 1984: 19: 263-268.

6. Mustard R JR, Shanding B, Gillam J. The KASAI operation (hepatic portoenterostomy) for biliary atresia. Experience with 20 cases. $J$ Pediatr Surg 1979: 14: 511-514.

7. Altman R P, Chandra R, Lilly J R. Ongoing cirrhosis after successful porticoenterostomy in infants with biliary atresia. $J$ Pediatr Surg 1975: 10: 685-691.

8. Kasal M, Watanabe I, OHi R. Follow-up of longterm survivors after hepatic portoenterostomy for "non-correctable" biliary atresia. J Pediatr Surg 1975: 10: 173-182.

9. Gautier M, Jehan P, Odievre M. Histologic study of biliary fibrous remnants in 48 cases of extrahepatic biliary atresia: corrclation with post-operative bile flow restoration. I Pediatr Surg 1976: 89: 704-709.

10. Gautier M. L'atrésie des voies biliaires extra-hépatiques. Arch Franc Pediat (Suppl) 1979: 36: III-XII.

11. Gautier M, Eliot N. Extrahepatic biliary atresia: morphological study of 98 biliary remnants. Arch Pathol Lab Med 1981: 105: 397-402.

12. Gosseye S, Otte J B, De Meyer R, Maldague P. A histological study of extrahepatic biliary atresia. Acta Paediatr Belg 1977: 30: 85-90.

13. Chandra R S, Altmann R P. Ductal remnants in atresia. J Pediatr 1978: 93: 196-200.

14. Clement B, Emonard H, Rissel M, et al. Cellular origin of collagen and fibronectin in the liver. Cell Molec Biol 1984: 30: 489-496.

15. Sakakibara K, Umeda M, Saito S, Nagase S. Production of collagen and acidic glycosaminoglycans by an epithelial liver cell clone in culture. Exp Cell Res 1977: 110: 159-165.

16. Timpl R, Wick G, Gay S. Antibodies to distinct types of collagens and procollagens and their application in immunohistology. I Immunol Meth 1977: 18: 165 .

17. Grimaud J A, Druguet M, Peyrol S, et al. Collagen immunotyping in human liver: light and elec- tron microscope study. $J$ Histochem Cytochem 1980 : 28: $1145-1156$.

18. Rojkind M, Ponce-Noyola P. The extracellular matrix of the liver. Collagen Rel Res 1982: 2: 151-175.

19. Ouaissi M A, Afchain B, Capron A, et al. Fibronectin receptors or Trypanosoma cruzi trypomastigotes and their biological function. Nature 1984: 308: $380-382$.

20. Takiya Ch, Peyrol S, Cordier J F, et al. Connective matrix organization in human pulmonary $\mathrm{fi}^{-}$ brosis: collagen polymorphism analysis in fibrotic deposits by immunohistochemical methods. Virchou's Arch [Cell Pathol] 1983: 44: 223-240.

21. Ludwig J, Dickson E R, MCDonald G S A. Staging of chronic non-suppurative distructive cholangitis (syndrome of primary biliary cirrhosis). Virchows Arch /A/ 1978: 379: 103-112.

22. GabBiani $G$. The role of contractile proteins in wound healing and fibrocontractive diseases. Meth Arch Exp Pathol 1979: 9: 187-207.

23. Rungger-Brandle, Gabbiani G. Cytoskeleton in pathology. Am J Pathol 1983: 110: 359-384.

24. Seemayer T A, Schurch W, Lagace R. Myofibroblasts in human pathology. Hum Pathol 1981: 12: 491-492.

25. Barsky S H, Green W R, Grotendorst G R, LiotTA L A. Desmoplastic breast carcinoma as a source of human myofibroblasts. Am J Pathol 1984: 115: $329-333$.

26. Kischer C W, Rhies A C, Chvapil M. Perivascular myofibroblasts and microvascular occlusion in hypertrophic scars and keloids. Hum Pathol 1982: 13: 819-824.

27. Baur P S, Barratt G F, Brown G M, Parks D J. Ultrastructural evidence for the presence of "fibroclasts" and "myofibroclasts" in wound healing tissues. J Trauma 1979: 19: 744-756.

28. Schurch W, Seemayer T A, Lagace R. Stromal myofibroblasts in primary invasive and metastatic carcinomas. A combined immunological light and electron microscopic study. Virchows Arch [A] 1981: 391: 125-139.

29. Schurch W, Lagace R, Seemayer T A. Myofibroblastic stromal reaction in retracted scirrhous carcinoma of the breast. Surg Gynecol Obstet 1982: 154: 351-358.

Address:

L. A. R. de Freitas

Laboratoire de Pathologie Cellulaire du Foie

CNRS ERA 819

Institut Pasteur

77 rue Pasteur

69365 Lyon cedex 7

France 